\title{
Coronary Aneurysms in a Case of Ehlers-Danlos Syndrome
}

\author{
Carlo Di Mario, M.D., Mario Zanahetta, M.D., \\ and Pietro Maiolino, M.D.
}

\begin{abstract}
Summary
An asymptomatic 48 year old man had transient T-wave inversion in the anterolateral leads after nonpenetrating chest trauma. Both the patient and his 6 year old son showed the typical skin hyperelasticity and joint hyperextensibility of the Ehlers-Danlos syndrome, suggesting autosomal dominant inheritance. The coexisting cardiac abnormalities of the patient included multiple coronary aneurysms, mitral valve prolapse with slight regurgitation, fusiform dilatation of the ascending aorta with moderate insufficiency and left anterior hemiblock. A routine noninvasive cardiovascular evaluation should be performed in all patients with EhlersDanlos syndrome in order to exclude valvular heart disease and dilatation of the aortic root or of other vessels, including the coronary arteries.
\end{abstract}

\section{Additional Indexing Words:}

Congenital coronary anomalies Ehlers-Danlos syndrome

$\mathrm{E}$

HLERS-DANLOS syndrome is an inherited connective tissue disorder manifested by hypermobility of the joints and hyperextensibility of the skin, associated with a large variety of coexistent visceral abnormalities. Multiple cardiovascular diseases have been reported, ${ }^{1}{ }^{1}$ including aortic insufficiency, ${ }^{2,31}$ mitral valve prolapse, ${ }^{4-6)}$ aneurysms of the sinuses of Valsalva,7) arterial aneurysms ${ }^{8)}$ and cardiac conduction tissue defects. ${ }^{6)}$

We describe a case of autosomal dominant Ehlers-Danlos syndrome with multiple cardiovascular abnormalities, including right and left coronary aneurysms.

\section{Case Report}

A 48 year old man, admitted to a Surgical Department because of head and chest trauma resulting from a traffic accident, showed left anterior hemi-

From the Cardiology Department, Cittadella General Hospital, Padova, Italy.

Address for reprints: Pietro Maiolino, M.D., Divisione Cardiologica, Presidio Ospedaliero U.L.S.S. 19, 35013 Cittadella, Padova, Italy.

Received for publication August 17, 1987.

Accepted September 28, 1987. 


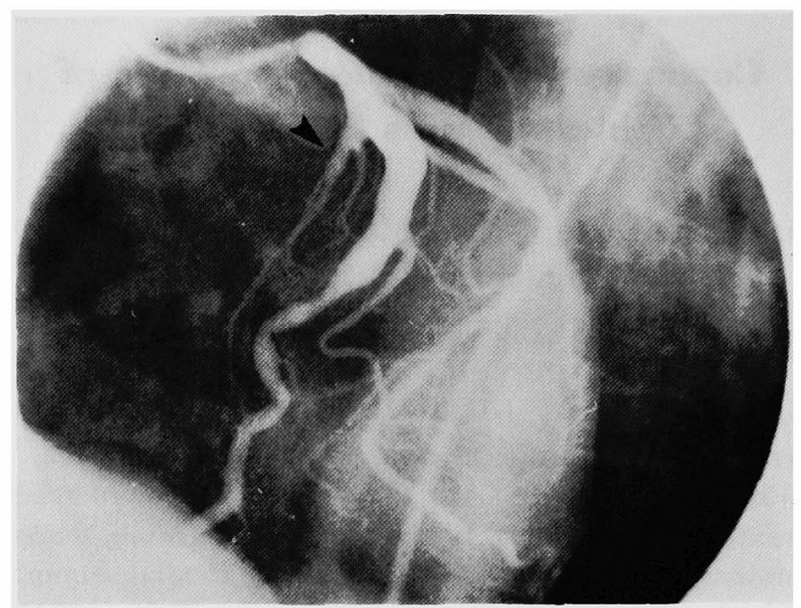

Fig. 1. Single angiogram showing the left coronary artery $\left(30^{\circ}\right.$ cranial, $30^{\circ}$ left anterior oblique view). The left anterior descending artery has a proximal, diffuse dilatation (maximal diameter: $10 \mathrm{~mm}$ ) with smooth edges, involving the first septal branch (arrow) and ending in a progressive narrowing. Smaller multiple aneurysms of the distal left anterior descending artery were also observed.

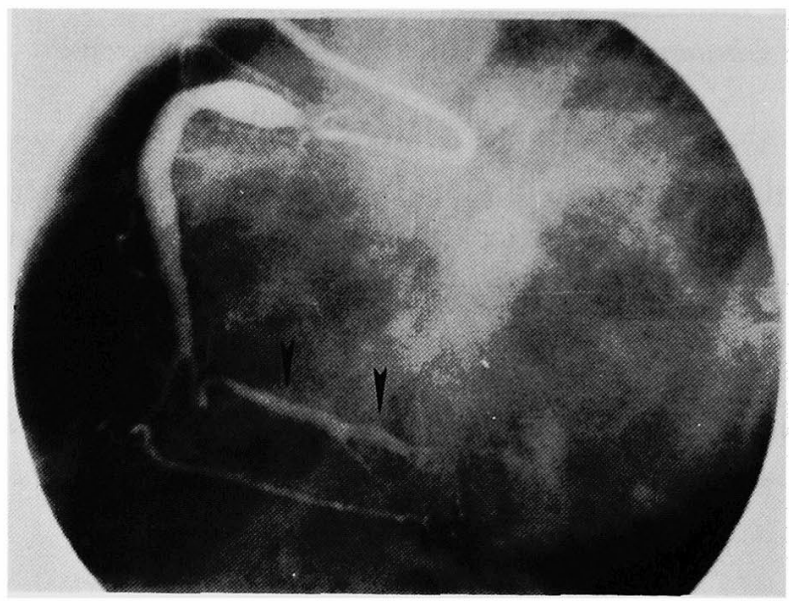

Fig. 2. Single angiogram showing the right coronary artery $\left(45^{\circ}\right.$ left anterior oblique view). A large (maximal diameter: $8 \mathrm{~mm}$ ) fusiform aneurysm involves the proximal and intermediate segments of the vessel, immediately after the coronary ostium, which appears falsely narrowed. Arrows indicate a distal coronary aneurysm.

block and deep, negative, symmetrical $T$-waves in $\mathrm{D}_{1}-\mathrm{a} \mathrm{V}_{\mathrm{L}}$ and $\mathrm{V}_{3^{3}}-\mathrm{V}_{6}$. No concomitant enzymatic changes were observed. Despite the disappearance of the electrocardiographic changes in the following 2 months and the absence of subjective symptoms, the patient was referred to the Cardiology Department 
of our hospital. Past history included a hemorrhoidectomy and an adenoidectomy.

At physical examination the patient appeared older than his age. The skin had a soft, velvety texture and was excessively stretchable, mainly on his knees and elbows, but no papyracious scars or pseudotumors were evident. A high and arched palate, moderate hyperextensibility of fingers, wrists and toes and bilateral pes planus were also observed.

At heart examination normal tones, no clicks, a grade 2/6 mesotelesystolic murmur at the apex and a high-pitched blowing diastolic rumble along the left sternal border could be heard. Of the laboratory analyses only bilirubinemia was above the normal limits $(26.7 \mu \mathrm{Mol} / 1)$, with a prevalent indirect fraction, and increased after a 48 hour fasting period $(43.6 \mu \mathrm{Mol} / 1)$. Therefore, Gilbert's syndrome was suspected.

The electrocardiogram at rest and during maximal, symptom-limited bicycle ergometric testing showed no ST-T abnormalities. The exercise test induced a normal increase in heart rate and systemic arterial pressure, without any subjective complaints.

Echocardiography showed normal dimensions of the left ventricular cavity with normokinetic walls, diastolic fluttering of the anterior leaflet of the mitral valve and mesotelesystolic prolapse of both mitral leaflets into the left atrium.

Left and right heart catheterization was performed through the percutaneous femoral route without hemorrhagic complications at puncture sites, and showed a minimal increase in the end-diastolic left ventricular volume $\left(97 \mathrm{ml} / \mathrm{m}^{2}\right)$, a normal left ventricular ejection fraction $(75 \%)$ and a slight mitral insufficiency. Biplane supravalvular cineaortography showed a moderate fusiform ectasia of the ascending aorta, a tricuspid aortic valve and moderate aortic regurgitation. The large, fusiform coronary aneurysms observed during selective coronary angiography are shown in Figs. 1 and 2.

Coexisting aneurysms of the intracranial, celiac, renal and subclavian arteries could be excluded by digital subtraction angiography. A double right renal artery was observed, inducing a partial pyeloureteral stenosis and a secondary dilatation of the calico-pyelic cavities.

Clinical, electrocardiographic and echocardiographic examinations were also performed on the patient's two daughters and one son. Only the 6 year old son showed skin hyperelasticity and joint hyperextensibility, QRS left axial deviation and echocardiographic evidence of a mesotelesystolic mitral valve prolapse. 


\section{Discussion}

The most common etiologic factors of coronary artery aneurysms are atherosclerosis ${ }^{10)}$ or systemic inflammatory diseases (systemic medionecrosis, panarteritis nodosa, scleroderma, Kawasaki syndrome, ${ }^{11)}$ etc). Congenital aneurysms are rare and almost never diagnosed in life. ${ }^{12)-15)}$ In particular, in patients with Ehlers-Danlos syndrome, saccular aneurysms of the right coronary artery, filled with thrombi, have been described in association with a history of myocardial infarction and with aneurysms of cerebral vessels, upper and lower limb arteries, splenic and mesenteric arteries.9' In our patient the aneurysms had a smaller diameter, were fusiform, without angiographic evidence of mural thrombosis, and involved both the right and left coronary arteries. Fusiform aneurysmal dilatations of the coronary arteries have been described in association with an idiopathic mitral valve prolapse, ${ }^{13)}$ but not in the context of the multiple cardiovascular manifestations of the Ehlers-Danlos syndrome.

Ehlers-Danlos syndrome includes several distinguishable types, characterized by different inheritance modalities and heterogeneous phenotypic manifestations. The "arterial" type (type IV ${ }^{16)}$ or Sack-Barabas type ${ }^{17)}$ ) has been associated with abnormalities in the metabolism of type III collagen and is characterized by mild joint hyperextensibility and moderate skin hyperelasticity. Its poor reputation is mainly due to proneness to spontaneous rupture of vessels and colon. Although a recessive form of type IV Ehlers-Danlos syndrome has been documented, ${ }^{18}$ most of the patients have an autosomal dominant inheritance, as in our case.

The transient electrocardiographic signs of myocardial ischemia followed nonpenetrating chest trauma and were probably related to damage of the dilated segments of the coronary arteries, resulting in partial mural thrombosis and peripheral embolization. However, a direct myopericardial contusion cannot be excluded. In contradistinction, a traumatic etiology of the coronary aneurysms is not likely because of the diffuse involvement of the coronary tree.

Although two-dimensional echocardiography could not identify the dilated coronary segments of our patient, previous reports suggest that echocardiography can detect coronary aneurysms in most cases ${ }^{191,20)}$ and can be clinically helpful in selecting those patients requiring further angiographic evaluation.

\section{Conclusion}

A thorough cardiovascular examination should be performed on all pa- 
tients and relatives of patients with Ehlers-Danlos syndrome in order to exclude coexisting valvular insufficiencies and to detect vascular malformations. The presence of coronary aneurysms should be borne in mind as a possible cardiovascular abnormality in this syndrome.

\section{AGKNOWLEDGMENTS}

We are indebted to Carlo Baccichetti, Professor of Genetics at the University of Padua, for his clinical assistance and interest in the case. We thank Mr. Antonio Boaretto for his photographic assistance and Mrs. Ornella Pilotto for typing the manuscript.

\section{REFERENCES}

1. Beighton P: Cardiac abnormalities in the Ehlers-Danlos syndrome. Br Heart J 31: 227, 1969

2. Simon PA, Stein PD: Aortic insufficiency in Ehlers-Danlos syndrome. Angiology 25: 290, 1974

3. Edmondson $P$, Nellen $M$, Ross DN: Aortic valve replacement in a case of Ehlers-Danlos syndrome. Br Heart J 42: 103, 1979

4. Brandt KD, Sumner RD, Ryan TJ, Cohen AS: Herniation of mitral leaflets in the EhlersDanlos syndrome. Am J Cardiol 36: 524, 1975

5. Madison WM, Bradley EJ, Castillo AJ: Ehlers-Danlos syndrome with cardiac involvement, Am J Cardiol 11: 689, 1963

6. Cabeen WR, Reza MJ, Kovick RB, Stern MS: Mitral valve prolapse and conduction defects in the Ehlers-Danlos syndrome. Arch Intern Med 137: 1227, 1977

7. Tucker DH, Miller DE, Jacoby WJ: Ehlers-Danlos syndrome with a sinus of Valsalva aneurysm and aortic insufficiency simulating rheumatic heart disease. Am J Med 35: 715, 1963

8. McFarland W, Fuller DE: Mortality in Ehlers-Danlos syndrome due to spontaneous rupture of large arteries. New Engl J Med 271: 1309, 1964

9. Imahori S, Bannermann RM, Graaf CJ, Brennan JC: Ehlers-Danlos syndrome with multiple arterial lesions, Am J Med 47: 967, 1969

10. Swaye PS, Fisher LD, Litwin P, Vignola PA, Judkins MP, Kemp HG, Mudd JG, Gosselin AJ: Aneurysmal coronary artery disease. Circulation 67: 134, 1983

11. Onouchi Z, Shimazu S, Kiyosawa N, Takamatsu T, Hamaoka K: Aneurysms of the coronary arteries in Kawasaki disease. An angiographic study of 30 cases. Circulation 66: 6, 1982

12. Seabra-Gomes R, Sommerville J, Ross DN, Emanuel R, Parker DJ, Wong M: Congenital coronary artcry aneurysms. Br Heart J 36: 329, 1974

13. Dianzumba SB, Kumar S: Mitral valve prolapse and coronary artery ectasia. Cath Cardiovasc Diagn 4: 207, 1978

14. Stone DL, Fleming HA: Aneurysm of left ventricle and left coronary artery after nonpenetrating chest trauma. Br Heart J 50: 495, 1983

15. Konecke LL, Spitzer S, Mason D, Kasparian H, James PM: Traumatic aneurysm of the left coronary artery. Am J Cardiol 27: 221, 1971

16. McKusick VA: Autosomal dominant inheritance. in Mendelian Inheritance in Man, ed by McKusick VA, Johns Hopkins University Press, Baltimore, p 217, 1986

17. Byers PH, Holbrook KA, McGillivray B, MacLeod PM, Lowry RB: Clinical and ultrastructural heterogeneity of type IV Ehlers-Danlos syndrome. Hum Genet 47; 141, 1979

18. Pope FM, Martin GR, McKusick VA: Inheritance of Ehlers-Danlos type IV syndrome. 
J Med Genet 14: 200, 1977

19. Fujiwara T, Fujiwara H, Ueda T, Nishioka K, Hamashima Y: Comparison of macroscopic, post-mortem, angiographic and two-dimensional echocardiographic findings of coronary aneurysms in children with Kawasaki disease. Am J Cardiol 57: 761, 1986

20. Capannari TE, Daniels SR, Meyer RA, Schwartz DC, Kaplan S: Sensitivity, specificity and predictive value of two-dimensional echocardiography in detecting coronary artery aneurysms in patients with Kawasaki disease. J Am Coll Cardiol 7: 355, 1986 